\title{
PENGARUH UKURAN PERUSAHAAN TERHADAP MANAJEMEN LABA DENGAN STRUKTUR MODAL SEBAGAI VARIABEL MODERASI
}

\section{THE EFFECT OF COMPANY SIZES ON EARNING MANAGEMENT WITH CAPITAL STRUCTURE AS MODERATED VARIABLES}

\author{
Inge Lengga Sari Munthe \\ Universitas Maritim Raja Ali Haji - Tanjungpinang \\ Email : ingemunthe@yahoo.com
}

\begin{abstract}
ABSTRAK
Penelitian ini bertujuan untuk menganalisa pengaruh ukuran perusahaan terhadap manajemen laba dengan struktur modal sebagai variabel moderasi di perusahaan subsektor tekstil dan garmen di Bursa Efek Indonesia tahun 2015-2018. Metode pengambilan sampel dengan purposive sampling. Terdapat 16 sampel perusahaan. Metode penelitian dengan uji statistik dimana juga menggunakan uji analisis regresi moderasi. Hasillnya adalah secara simultan dan parsial ukuran perusahaan dan struktur modal berpengaruh terhadap manajemen laba. Struktur modal juga dapat memperkuat pengaruh antara ukuran perusahaan dengan manajemen laba.
\end{abstract}

Kata Kunci :Ukuran Perusahaan, Struktur Modal, Manajemen Laba, Variabel moderasi.

\section{ABSTRACT}

This research aims to analyze the effect company size to earning management with capital structure as moderating variable in sub sector textile and garment in Bursa Efek Indonesia from 2015 until 2018.. It uses purposive sampling to take sample. There are 16 companies as samples. Reseach method with statistic test where use moderating regression analysis. The results are company size and capital structure have effect on earning management for simltaneously and partial respectively. Capital structure also strength the effect beween company size with earning management.

Keywords :Company Size, Capital Structure, Earning Management, Moderating Variable.

\section{PENDAHULUAN}

Laporan keuangan adalah sekumpulan laporan yang berisi informasi kuantitatif dan kualitatif selama satu periode tertentu. Laporan keuangan terdiri dari : laporan laba rugi, laporan perubahan modal, laporan posisi keuangan, laporan arus kas dan catatan atas laporan

keuangan. Pihak-pihak yang berkepentingan terhadap laporan keuangan adalah : manajemen perusahaan, investor, pemerintah dan kreditur. Sebagai pihak yang berkepentingan, salah satu yang dilihat dari laporan keuangan adalah laba perusahaan. Laba merepresentasikan kinerja perusahaan yang dihasilkan selama satu periode tertentu. Bila laba tinggi, diasumsikan bahwa perusahaan itu baik. Bila laba turun, diindikasikan bahwa perusahaan itu ada masalah.Laba juga dapat dipakai untuk memprediksi berapa dividen yang bias dibayar, menilai kinerja manajemen, berapa yang bias untuk membayar utang atau berapa yang bias untuk membeli asset tetap baru. 
Laba yang tinggi adalah indikasi perusahaan yang bagus, terlepas dari proses mendapatkan laba tersebut. Untuk membuat laba yang kelihatan bagus itu, pihak manajemen juga melakukan tindakan untuk "mempercantik laba". Hal inilah yang dinamakan manajemen laba. Manajemen laba terjadi ketika manajemen menggunakan keputusan tertentu dalam pelaporan keuangan dan penyusunan transaksi-transaksi yang mengubah laporan keuangan. Hal ini bertujuan untuk menyesatkan para stakeholders mengenai kondisi kinerja ekonomi perusahaan, serta untuk mempengaruhi penghasilan kontraktual yang mengendalikan angka akuntansi yang dilaporkan (Beneish, 1989 dalam Izzah, 2016).

Struktur modal merupakan kebijakan pendanaan dari perusahaan. Pendanaan perusahaan diperlukan untuk memperkuat perusahaan dalam hal pembelian asset atau penambahan modal kerja. Dalam memperoleh asset, umumnya perusahaan meminjam uang ke pihak lain. Hal ini menyebabkan asset semakin besar, tapi juga utang semakin besar.

Ukuran perusahaan akan berpengaruh terhadap kemudahan perusahaan dalam memperoleh hutang. Perusahaan besar memiliki aktiva yang besar yang dapat dijaminkan dalam sumber pendanaan. Sehingga ukuran perusahaan akan berpengaruh terhadap akses perusahaan untuk memperoleh sumber pendanaan. Semakin tinggi proporsi hutang maka semakin tinggi harga saham, namun pada titik tertentu peningkatan hutang akan menurunkan nilai perusahaan karena manfaat yang dioeroleh dari penggunaan hutang lebih kecil dari pada biaya yang ditimbulkannya (Nuraina, 2012).

Berdasarkan uraian diatas,maka perumusan masalah adalah sebagai berikut : 1) Apakah Struktur Modal berpengaruh terhadap manajemen laba; 2) Apakah ukuran perusahaan berpengaruh terhadap manajemen laba; 3) Apakah Struktur modal dapat memoderasi hubungan ukuran perusahaan terhadap manajemen laba.

\section{LANDASAN TEORI}

\section{Manajemen Laba}

Fischer dan Rosenzweig (1995) mendefinisikan manajemen laba sebagai tindakan seorang manajer dengan menyajikan laporan yang menaikan (menurunkan) laba periode berjalan dari unit usaha yang menjadi tanggungjawabnya, tanpa menimbulkan kenaikan (penurunan) profitabilitas ekonomi unit tersebut dalam jangka panjang. Schipper (1989) mendefinisikan manajemen laba sebagai suatu intervensi dengan maksud tertentu terhadap proses pelaporan keuangan eksternal dengan sengaja untuk memperoleh beberapa keuntungan pribadi. (Nanok, et.al,2010).

Ada 4 pola manajemen laba yaitu (Aryati, 2017):

1. Income Minimization. Cara ini dilakukan pada saat profitabilitas perusahaan sangat tinggi dengan maksud agar tidak mendapat perhatian secara politis. Kebijakan yang diambil dapat berupa penghapusan (write offs) atas barang modal dan asset tak berwujud, pembebanan pengeluaran iklan, riset dan pengembangan yang cepat, memilih metode succesful-effort untuk biaya eksplorasi gas dan minyak bumi, dan sebagainya.

2. Income Smoothing. Hal ini dilakukan dengan meratakan laba yang dilaporkan untuk tujuan pelaporan eksternal, terutama bagi investor karena pada umumnya investor lebih menyukai laba yang relatif stabil.

3. Income Maximization. Maksimalisasi laba dimaksudkan untuk memperoleh bonus yang lebih besar, dimana laba yang dilaporkan tetap dibawah cap. Juga untuk menghindar dari pelanggaran atas kontrak hutang jangka panjang (debt covenant). Cara ini dapat ditempuh dengan mengubah metode atau asumsi akuntansi ke yang lebih liberal. 
4. Taking A Bath. Teknik ini mengakui adanya biaya-biaya pada periode yang akan datang dan kerugian periode berjalan ketika keadaan buruk yang tidak menguntungkan tidak bisa dihindari pada periode berjalan. Konsekuensinya, manajemen "menghapus" beberapa asset, membebankan perkiraan-perkiraan yang mendatang, dan melakukan "clear the decks".

Menurut Setiawati dan Na'im (2000) manajemen laba dapat dilakukan dengan tiga teknik, yaitu:(Kusumawardhani, 2012)

1) Memanfaatkan peluang untuk membuat estimasi akuntansi;

2) Mengubah metode akuntansi;

3) Menggeser periode biaya atau pendapatan.

\section{Ukuran Perusahaan}

Ukuran perusahaan merupakan salah satu indikator yang digunakan investor dalam menilai aset maupun kinerja perusahaan. Ukuran perusahaan dapat dilihat dari total aktiva (asset) dan total penjualan (net sales) yang dimiliki oleh perusahaan.) mengemukakan bahwa perusahaan yang berukuran lebih besar cenderung memiliki informasi lebih tinggi dibandingkan dengan perusahaan yang lebih kecil. Semakin besar ukuran perusahaan biasanya informasi yang tersedia untuk pengambilan keputusan dalam perusahaan tersebut semakin banyak. Semakin besar suatu perusahaan, semakin besar pula kemampuan untuk mendapat pinjaman karena perusahaaan besar relatif lebih mampu untuk menghasilkan laba. Mawarta (2000) dalam Ekarini (2006). Semakin besar ukuran perusahaan, maka semakin kecil pengelolaan laba yang dilakukan oleh perusahaan, di mana perusahaan-perusahaan kecil lebih cenderung melakukan pengelolaan laba dibandingkan perusahaan besar (Kusumawardhani,2012).

\section{Struktur Modal}

Struktur modal merupakan pendanaan yang terdiri dari utang dan modal. Dharmastuti et al (2003) menyatakan bahwa hutang merupakan salah satu sumber pembiayaan eksternal yang digunakan oleh perusahaan untuk membiayai kebutuhan dananya. Dalam pengambilan keputusan penggunaan hutang ini harus mempertimbangkan besarnya biaya tetap yang muncul dari hutang berupa bunga yang akan menyebabkan semakin meningkatnya leverage keuangan dan semakin tidak pastinya tingkat pengembalian bagi para pemegang saham biasa. Tingkat penggunaan hutang dari suatu perusahaan dapat ditunjukkan oleh salah satunya menggunakan rasio hutang terhadap ekuitas (DER), yaitu rasio jumlah hutang terhadap jumlah modal sendiri.(Nuraina, 2012).

\section{PENGEMBANGAN HIPOTESIS}

Ukuran perusahaan menggambarkan besarnya perusahaan dalam bentuk total asset. Perusahaan yang mempunyai total asset besar, cenderung untuk melakukan laba yang lebih benar. Hal ini karena ada reputasi perusahaan yang harus dipertaruhkan. Tetapi ada juga perusahaan yang asetnya besar melakukan manajemen laba karena adanya tekanan-tekanan dari pihak manajemen. Dengan melakukan manajemen laba, maka perusahaan juga mendapat nama yang tetap terjaga baik.

Hipotesis 1 : Diduga ukuran perusahaan berpengaruh terhadap manajemen laba.

Struktur modal merupakan proporsi pendanaan dalam bentuk utang dan modal. Perusahaan yang ingin menambah utang, cenderung untuk melakukan manajemen laba agar dipercaya 
meminjam uang. Kreditur akan melihat kesanggupan perusahaan dalam membayar utang dari laba yang dihasilkan. Bila dilihat labanya semakin membaik, kreditur tidak akan segan-segan untuk memberikan pinjaman lagi ke perusahaan.

Hipotesis 2 : Diduga struktur modal berpengaruh terhadap manajemen laba.

Salah satu tindakan yang dilakukan untuk menambah jumlah asset, adalah dengan berutang. Utang tersebut dapat digunakan untuk membeli asset tetap, agar kegiatan operasional perusahaan dapat berjalan lebih baik. Untuk itu perusahaan melakukan manajemen laba, agar dapat mendapat pinjaman dengan salah satu tujuan untuk memperbesar asset.

Hipotesis 3 : Diduga struktur modal dapat memoderasi ukuran perusahaan dengan manajemen laba.

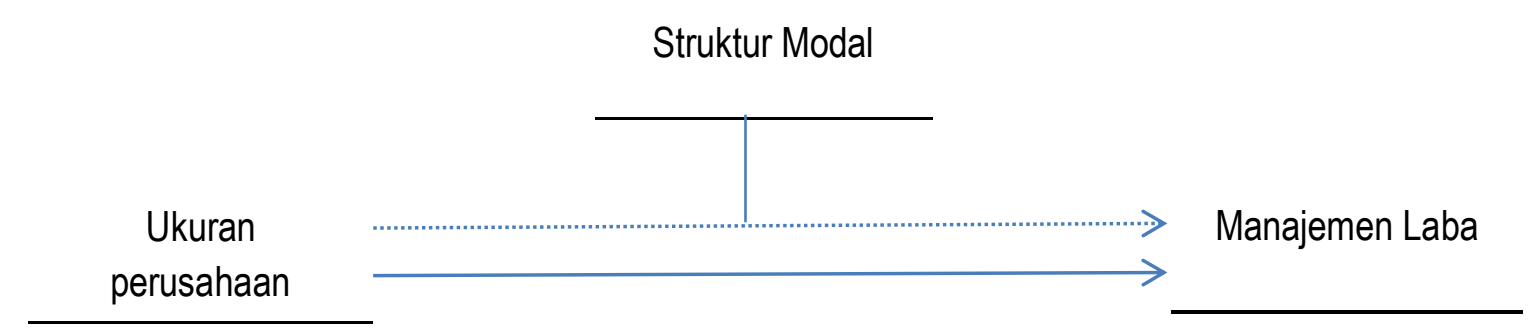

Gambar : Kerangka Pemikiran

\section{METODOLOGI PENELITIAN}

Jenis data yang dipakai adalah data sekunder. Sumber data penelitian adalah berasal dari idx.go.id. Populasi yang dipakai adalah perusahaan subsektor tekstil dan garmen di Bursa Efek Indonesia tahun 2015-2018. Pengambilan sampel adalah dengan purposive sampling. Terdapat 16 sampel perusahaan, dengan waktu 3 tahun. Sehingga terdapat 48 data dalam penelitian ini.

\section{Metode Analisis dan Hipotesis}

Metode analisis data adalah dengan menggunakan uji statistik. Berikut tahapannya :

1. Uji Asumsi Klasik, meliputi uji normalitas dan uji linieritas.

2. Uji Hipotesis berupa : uji koefisien $\mathrm{R}^{2}$, uji parsial (uji t), uji simultan (uji F) dan analisis regresi moderasi.

Langkah analisis adalah sebagai berikut :

1. Uji regresi berganda dari Total Aset ( $\left.X_{1}\right)$ dan Struktur Modal ( $Z$ ) ke Manajemen laba ( $Y)$.

2. Uji regresi berganda dari Total Aset $\left(X_{1}\right)$, Struktur Modal $(Z)$ dan Struktur modal * Total Aset ( interaksi $Z{ }^{*} X_{1}$ ) ke Manajemen laba $(Y)$. 


\section{Operasionalisasi Variabel Penelitian}

1. Manajemen laba diprosikan dengan discretionary accrual dari Modified Jones Model. Berikut tahap-tahap (Sulistyanto, 2008) :

$>$ Menghitung Total Accrual.

Total Accrual (TAC) $=$ Net Income - Cash Flow from operating activities)

$>$ Menghitung Nilai Akrual dibandingkan total aset tahun sebelumnya.

$T A C_{t} / A_{t-1}=\alpha_{1}\left(1 / A_{t-1}\right)+\alpha_{2}\left(\Lambda R E C_{t} / A_{t-1}\right)+\alpha_{3}\left(P P E_{t} / A_{t-1}\right)+e$

Bila sudah didapat koefisien $\boldsymbol{\alpha}_{1}, \boldsymbol{\alpha}_{2}, \boldsymbol{\alpha}_{3}$, kemudian koefisien-koefisien ini dimasukkan ke persamaan berikut ini, untuk menghitung non discretionary accruals (NDA) :

$N D A_{t}=\alpha_{1}\left(1 / A_{t-1}\right)+\alpha_{2}\left(\left(\wedge R E V_{t}-\wedge R E C_{t}\right) / A_{t-1}\right)+\alpha_{3}\left(P P E_{t} / A_{t-1}\right)$

$>$ Menghitung discretionary accruals.

$>\mathrm{DAC}_{\mathrm{t}}=\left(\mathrm{TAC}_{\mathrm{t}} / \mathrm{A}_{\mathrm{t}-1}\right)-\mathrm{NDA}_{\mathrm{t}}$

Net Income = Laba Bersih setelah pajak

Cash Flow from operating activities $=$ arus kas operasi

$\mathrm{TAC}_{\mathrm{t}} \quad=$ Total Accruals perusahaan i pada periode $\mathrm{t}$

$\mathrm{A}_{\mathrm{t}-1}=$ Total Aset perusahaan i pada periode $\mathrm{t}-1$

$\triangle \mathrm{REC}_{\mathrm{t}}=$ Perubahan piutang dari tahun $\mathrm{t}-1$ ke tahun $\mathrm{t}$

$\mathrm{PPE}_{\mathrm{t}} \quad=$ Aset Tetap pada tahun $\mathrm{t}$

$\mathrm{NDA}_{\mathrm{t}} \quad=$ Non discretionary accruals pada tahun $\mathrm{t}$

$\Lambda R E V_{t} \quad=$ Perubahan pendapatan dari tahun $\mathrm{t}-1$ ke tahun $\mathrm{t}$

a $=$ fitted coefficient yang diperoleh dari hasil regresi pada perhitungan total accruals

DAC $_{\mathrm{t}} \quad=$ Discretionary Accrual pada tahun $\mathrm{t}$

2. Ukuran Perusahaan $=$ Total Aset

3. Struktur modal proksinya adalah Debt to Equity Ratio ( DER ). Berikut rumusnya

$$
\mathrm{DER}=\frac{\text { Total Debt }}{\text { Total Equity }}
$$

\section{HASIL DAN PEMBAHASAN}

Uji regresi berganda dari Total Aset ( $\left.X_{1}\right)$ dan Struktur Modal ( $Z$ ) ke Manajemen laba ( $Y$ ).

Dari uji statistic didapat hasil sebagai berikut : 
ANOVA $^{\mathrm{a}}$

\begin{tabular}{|ll|r|r|r|r|r|}
\hline Model & & Sum of Squares & df & Mean Square & F & Sig. \\
\hline 1 & Regression & .157 & 2 & .078 & 4.107 & $.023^{b}$ \\
& Residual & .860 & 45 & .019 & & \\
& Total & 1.017 & 47 & & & \\
\hline
\end{tabular}

a. Dependent Variable: MNJ

b. Predictors: (Constant), TA, DER

Dari hasil uji $\mathrm{F}$, secara keseluruhan Ukuran perusahaan dan Struktur modal berpengaruh terhadap manajemen laba. Hal ini dapat dilihat dari tingkat signifikansi yaitu 0.023 dibawah 0.025 .

Coefficients $^{\mathrm{a}}$

\begin{tabular}{|c|c|c|c|c|c|c|}
\hline \multirow{2}{*}{\multicolumn{2}{|c|}{ Model }} & \multicolumn{2}{|c|}{ Unstandardized Coefficients } & $\begin{array}{c}\text { Standardized } \\
\text { Coefficients }\end{array}$ & \multirow[b]{2}{*}{$t$} & \multirow[b]{2}{*}{ Sig. } \\
\hline & & $\mathrm{B}$ & Std. Error & Beta & & \\
\hline \multirow[t]{3}{*}{1} & (Constant) & -.125 & .025 & & -4.998 & .000 \\
\hline & DER & -.009 & .008 & -.157 & -1.126 & .046 \\
\hline & TA & .019 & .007 & .390 & 2.798 & .008 \\
\hline
\end{tabular}

a. Dependent Variable: MNJ

Dari hasil uji t, secara parsial Struktur Modal berpengaruh negative terhadap Manajemen Laba. Ini berarti bahwa semakin besar Struktur Modal, manajemen laba yang dilakukan semakin kecil. Sementara bila Struktur modal semakin kecil, maka manajemen laba yang dilakukan semakin besar juga.

Dari Ukuran perusahaan berpengaruh positif terhadap Manajemen Laba. Hal ini berarti bahwa semakin besar Ukuran perusahaan maka semakin besar juga manajemen laba yang dilakukan. Sebaliknya semakin kecil Ukuran Perusahaan, maka manajemen laba yang dilakukan juga semakin kecil.

Uji regresi berganda dari Total Aset $\left(X_{1}\right)$, Struktur Modal $(Z)$ dan Struktur modal * Total Aset ( interaksi $Z{ }^{*} X_{1}$ ) ke Manajemen laba ( $Y$ ).

Dari hasil uji statistic sebagai berikut :

\begin{tabular}{|c|c|c|c|c|c|c|}
\hline \multicolumn{7}{|c|}{ Coefficients $^{a}$} \\
\hline \multirow{2}{*}{\multicolumn{2}{|c|}{ Model }} & \multicolumn{2}{|c|}{ Unstandardized Coefficients } & $\begin{array}{l}\text { Standardized } \\
\text { Coefficients }\end{array}$ & \multirow[b]{2}{*}{$t$} & \multirow[b]{2}{*}{ Sig. } \\
\hline & & B & Std. Error & Beta & & \\
\hline \multirow[t]{4}{*}{1} & (Constant) & -.116 & .027 & & -4.363 & .000 \\
\hline & DER & -.016 & .011 & -.281 & -1.485 & .145 \\
\hline & TA & .010 & .011 & .209 & .897 & .374 \\
\hline & DERTA & .006 & .006 & .272 & .970 & .038 \\
\hline
\end{tabular}

a. Dependent Variable: MNJ

Dari hasil statistic diatas, didapat bahwa Struktur Modal dapat memoderasi Ukuran Perusahaan terhadap Manajemen Laba. 


\section{Pembahasan}

1. Struktur Modal berpengaruh negative terhadap Manajemen Laba. Untuk mendapatkan pinjaman yang lebih besar, maka perusahaan melakukan manajemen laba yang besar juga. Hal ini agar dapat menjadi tanda bagi kreditur dalam memberikan pinjaman. Dengan laba yang semakin baik, kreditur dapat menghitung kemampuan perusahaan dalam membayar utangnya tepat waktu. Tapi bila laba dari tahun ke tahun semakin kecil, maka kreditur juga tidak bias memberikan pinjaman. Hal ini karena ketakutan kreditur terhadap kemampuan perusahaan dalam membayar utang.

2. Ukuran Perusahaan berpengaruh positif terhadap Manajemen Laba. Sebagai perusahaan besar, ada citra yang harus dipertaruhkan. Untuk mempertahankan citra ini, maka semakin besar perusahaan maka semakin besar juga manajemen laba yang dilakukan. Hal ini akan membuat investor percaya, sehingga lebih dapat menanamkan modal ke perusahaan. Ukuran perusahaan juga ada asset tetap. Aset tetap mempunyai beban penyusutan. Karena beban penyusutan bersifat akrual, maka bias saja beban penyusutan periode ini akan diakui di periode mendatang. Atau dengan mengubah metode penyusutan di tengah-tengah umur ekonomis.

3. Struktur Modal dapat memperkuat pengaruh Ukuran Perusahaan terhadap Manajemen Laba. Untuk mendapat pinjaman dalam tujuan memperbesar asset,maka perusahaan melakukan manajemen laba. Semakin baik laba, maka semakin bertambah keyakinan kreditur dalam memberikan pinjaman ke perusahaan.

\section{KESIMPULAN DAN SARAN}

\section{Kesimpulan}

1. Struktur Modal berpengaruh terhadap Manajemen Laba

2. Ukuran Perusahaan berpengaruh terhadap Manajemen Laba

3. Struktur Modal dapat memperkuat pengaruh Ukuran Perusahaan terhadap Manajemen Laba.

\section{Saran}

Agar dapat memperbanyak sampel dalam penelitian beserta variable penelitiannya.

\section{DAFTAR PUSTAKA}

Abdurrahim,"Mendeteksi Earning Management", Jurnal Akuntansi \& Investasi, Vol.1 no.2, ISSN : 1411-6227, hal.104-111.

Aditya, 2014, "Pengaruh Kualitas Auditor, Debt to Asset dan Ukuran Perusahaan terhadap Manajemen Laba, Skripsi, Universitas Maritim Raja Ali Haji, Tanjungpinang.

Aryati, 2017, "Earning Management", Kuliah Umum, Universitas Maritim Raja Ali Haji, Tanjungpinang.

Boediono, G S. B. 2005. "Kualitas Laba: Studi Pengaruh Mekanisme Corporate Governance dan Dampak Manajemen Laba dengan Menggunakan Analisa Jalur," Simposium Nasional Akuntansi VIII, Universitas Sebelas Maret, Surakarta. Dechow 
Elfira, 2009, "Pengaruh Kompensasi Bonus dan leverage terhadap Manajemen Laba", Skripsi, Universitas Negeri Padang.

Healy, Paul M, Wahlen, James M., 1999, "A review of the Earnings Management Literature and Its Implications for Standard Setting", Accounting Horizons, December 1999, vol.13, no.4, pp.365-383.

Hery, 2016, "Analisis Laporan Keuangan", Grasindo, Jakarta

Indriani, 2010, "Pengaruh Kualitas Auditor, corporate governance, leverage, dan kinerja keuangan terhadap manajemen laba", skripsi, Universitas Diponegoro, Semarang.

Kasmir, 2008, "Analisis Laporan Keuangan", Rajawali Pers, 2008.

Kusumawardhani, 2012, "Pengaruh Corporate Governance, Struktur Kepemilikan dan Ukuran Perusahaan terhadap Manajemen Laba", Jurnal Akuntansi dan Sistem Teknologi Informasi, vol.9, no.1, Oktober 2012,FE UPN "Veteran", Jogjakarta, hal.41-54.

Nanok, Natasya, Widadi, "Faktor-faktor yang mempengaruhi manajemen laba perusahaan publik di Indonesia 2008", Journal of Applied Finance and Accounting, vol.3 no.1, UNIKa Atmajaya, Jakarta, hal.60-74.

Nuraina, 2012, "Pengaruh Kepemilikan Institusional dan Ukuran Perusahaan terhadap kebijakan hutang dan nilai perusahaan", Jurnal Bisnis dan Ekonomi, vol.19, no.2,September 2012, IKIP PGRI, Madiun, hal.110-125.

Sudarmadji,Sularto, 2007, "Pengaruh Ukuran Perusahaan, profitabilitas, leverage dan tipe kepemilikan perusahaan terhadap luas voluntary disclosure laporan keuangan tahunan", proceeding PESAT, vol.2.

Susanti, "Faktor-faktor yang mempengaruhi manajemen laba perusahaan perbankan 2009-2014", Universitas Pandaran, Semarang. 